\title{
Minimally invasive posterior basilar segmentectomy by a posterior approach: Should we start flipping?
}

\author{
Eitan Podgaetz, MD, MPH, Gary S. Schwartz, MD, and David P. Mason, MD
}

\footnotetext{
From the Department of Thoracic Surgery and Lung Transplantation, Baylor University Medical Center, Center for Advanced Heart and Lung Disease, Dallas, Tex.

Disclosures: Authors have nothing to disclose with regard to commercial support.

Received for publication April 21, 2017; accepted for publication May 4, 2017; available ahead of print June 7, 2017.

Address for reprints: David P. Mason, MD, Department of Thoracic Surgery \& Lung Transplantation, Baylor University Medical Center, Center for Advanced Heart and Lung Disease, 3410 Worth St, Suite 545, Dallas, TX 75246 (E-mail: David.Mason@BSWHealth.org).

J Thorac Cardiovasc Surg 2017;154:1440-1

$0022-5223 / \$ 36.00$

Copyright (c 2017 by The American Association for Thoracic Surgery

http://dx.doi.org/10.1016/j.jtcvs.2017.05.012
}

The surgical management of small lung nodules located deep within the pulmonary parenchyma poses a dilemma for the thoracic surgeon, particularly in patients with marginal pulmonary function who may not tolerate lobectomy.

Multiple studies have demonstrated that sublobar resection is an acceptable treatment modality for small peripheral tumors without suggestive lymphadenopathy. ${ }^{1}$ Although wedge resection can be achieved thoracoscopically for peripheral lesions, lesions located deep in the lung parenchyma often require a segmentectomy or lobectomy to be certain to fully encompass the tumor. Segmentectomies are far less common than lobectomy and are significantly more technically demanding, even when performed via thoracotomy.

Nonetheless, there appears to be value to segmentectomy. On the basis of American College of Surgeons Oncology Group Z4302, patients had greater surgical parenchymal margins and higher rates of nodal upstaging when compared with wedge resection, ${ }^{2}$ suggesting improved oncologic efficiency. Defining the intersegmental planes for segmentectomy can be challenging, even during an open procedure. The majority of the segmentectomies that are performed are apical, superior segmental, and less commonly basilar. ${ }^{3}$ Some studies suggest that some segments have a higher rate of local recurrence, such as the apical segment of the right upper lobe and all basilar segments. ${ }^{4}$

From a technical standpoint, minimally invasive thoracoscopic segmentectomies are even more challenging technical operations. Specifically for basilar segmentectomies, one of the challenges emanates from the fact that the majority of video-assisted thoracic surgeons approach lung resections from an anterior approach where the dissection occurs from the hilum-anteriorly to posteriorly (fissureless) or directly in the plane of the interlobar fissure. On the basis of the anterior approach, it is technically difficult to visualize and perform a posterior or will not even try.

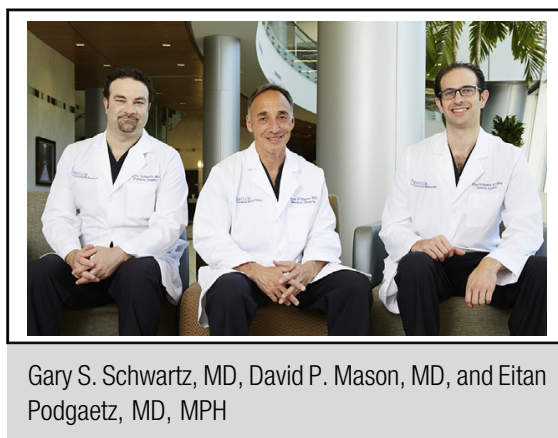

Central Message

This is an editorial on an article describing posterior segmentectomy.

See Article page 1432.

posterolateral basilar segmentectomy. Most surgeons

In this issue of the Journal, Endoh and colleagues ${ }^{5}$ from Yamagata University in Japan describe their experience with their pioneering posterior approach for performing minimally invasive thoracoscopic posterior and posterolateral basilar segmentectomies for lung nodules.

They describe the indications, pathology, and operative details, but really focus on the technical aspects of their operative approach and unique method for preoperative planning using multidetector computed tomography with 3-dimensional simulation to evaluate the individual segmental vascular and bronchial anatomy.

They also explain their approach to delineating the intersegmental plane using what they call the "slip-knot technique," in which the involved bronchial segment is divided and the surrounding parenchyma is inflated with the assistance of high-frequency jet ventilation during bronchoscopic evaluation, defining the offending segment. Then they use a combination of energy and stapling to divide the intersegmental plane.

The present study by Endoh and colleagues ${ }^{5}$ highlights the importance of thinking outside the box to find solutions for complex surgical scenarios. It is evident that their results are extraordinary and that they are a true testament to their dedication, knowledge, and excellent team approach for these complex problems.

Despite this, I believe that most surgeons reading this article would find it daunting to attack basilar lung nodules using their approach given the technical tour de force that is 
necessary to perform it. As we learn more about posterior minimally invasive thoracoscopic approaches to the chest and are able to incorporate them into our thoracic surgical training or as special courses during meetings, it may become easier for others to replicate the results of Endoh and colleagues. ${ }^{5}$ Until then, we congratulate the authors on a well-designed operation from a posterior surgical approach but caution the readers that this is a complex operation and not one for the novice video-assisted thoracic surgeon.

We thank the editors for the opportunity to comment on an important topic on the field of evolving minimally invasive thoracic surgery techniques in the management of deep-seated lung nodules.

\section{References}

1. El-Sherif A, Gooding WE, Santos R, Pettiford B, Ferson PF, Fernando HC, et al. Outcomes of sublobar resection versus lobectomy for stage I nonsmall cell lung cancer: a 13-year analysis. Ann Thorac Surg. 2006;82: 408-15.

2. Kent M, Landreneau R, Mandrekar S, Hillman S, Nichols F, Jones D, et al. Segmentectomy versus wedge resection for non-small cell lung cancer in high-risk operable patients. Ann Thorac Surg. 2013;96:1747-54.

3. Oizumi H, Kanauchi N, Kato H, Endoh M, Takeda S, Suzuki J, et al. Total thoracoscopic pulmonary segmentectomy. Eur J Cardiothorac Surg. 2009;36: 374-7.

4. Nishio W, Yoshimura M, Maniwa Y, Kitamura Y, Tane K, Takenaka D, et al. Reassessment of intentional extended segmentectomy for clinical T1aN0 non-small cell lung cancer. Ann Thorac Surg. 2016;102:1702-10.

5. Endoh M, Oizumi H, Kato H, Suzuki J, Watarai H, Masaoka T, Sadahiro M. Posterior approach to thoracoscopic pulmonary segmentectomy of the dorsal basal segment: a single-institute retrospective review. J Thorac Cardiovasc Surg. 2017; 154:1432-9. 